\title{
Analysis on the Art Style Formation about Huang Binhong's Landscape Painting
}

\author{
Wenxiu Li \\ College of Art and Design \\ Huanghe Science and Technology College \\ Zhengzhou, China
}

\begin{abstract}
Landscape painting master Huang Binhong through intensive study of traditional Chinese landscape painting, first learn from the predecessors, then learn from the nature, and combined the traditional pen and ink techniques with specific artistic themes to create a landscape painting art style with "black" as the main aesthetic feature which establish another artistic peak. Song and Yuan dynasty's traditional culture and Western culture had a significant impact on his art creation methods.
\end{abstract}

\section{Keywords-Huang Binhong; landscape painting; black light}

\section{ORIGINATED FROM THE DISINTEGRATION OF SONG AND YUAN DYNASTY'S AESTHETICS}

Development of landscape painting reached a golden age during the Song and Yuan dynasty, while inheriting the Five Dynasties' deep in nature describing the real beauty of mountains, he continue to make improvements, the content is extremely broad. Song landscape paintings have rigorous depiction and comprehensive techniques, dignified and quiet, layer by layer deposition full with ink painting meaning and artistic conception. To the Yuan Dynasty, due to the invasion of minorities, men of letters live in seclusion in order to escape the chaos; the dominator of Yuan Dynasty put physical above mental which makes more scholars engaged in painting. The seepage of Zen Buddhist concept of "Silence" and "Zen Interest" and the prosperity of literati paintings which advocate pen and ink interest make landscape painters of this period pay more attention to ink and pen interest and personal style. The aesthetic change of Yuan Dynasty landscape painting has brought a profound impact on the later development of Chinese landscape painting. The artistic interest simple and plain, elegant and free from vulgarity, sparse but graceful, quietly elegant, leisurely drawing does not seek the same shape, its quiet light naive aesthetic charm make the later landscape painting always pursue a simple, light and wind style. So that Dong Qichang from Late Ming dynasty has his aesthetic ideology of "light as the purpose" which advocate quiet, soft, simple and light aesthetic taste. This "light as the purpose" aesthetic complex to the Qing Dynasty, "Four Wang" landscape paintings degenerate into vulgar, soft, sweet and extravagant, painting form is old, some people are blindly into the state of imitating the ancient, but out of the nature, it can not get vivid things from nature so the paintings are relatively conservative and stubborn, the whole art circles has a lifeless situation. Huang Binhong's paintings show people with "black", change the previous dim nothingness style, break the "light" caged world, he boldly attempt to imitate the ancients and change into his own technique to open a generation of style. This "black" is not just a simple painting appearance, it contains the rich nourishment of the cultural spirit in Chinese nation for thousands of years, and it is the result for learning from the ancients and the nature.

\section{THE HEAVy CUltural Herit AGE}

\section{A. The Absorption of Different Cultures}

As can be seen from the sketches of ancient manuscript and sketch drafts, after his in-depth study of tradition and learning from famous painters' techniques, he concerned about the actual object, and found the basis for certain landscape in certain times, and then draw the sketch draft. So even for the sketch, since his deeply study of ancient technique and ancient theory, so his sketch draft has the almost the same form with the ancient manuscript draft. But we must understand that this almost the same is completely produced on the basis of his learning and understanding to the ancient people, it is necessity of learning and means to solve the problem, not the fur works. In Huang Binhong's "black" landscape paintings in his old age, we can intuitively understand the lifetime of work on tradition with his entire life, short pen with wrinkle rub reflect his versed technique. But when this old man who is faithful to the tradition faced the wave of Western Learning spreads to the East, from the initial defense for tradition, radical opinions to later learn and absorb Western art. His had studied with western impressionist, abstract and fauvism. Someone once said in Huang works, his point method is similar to Western painting strokes, but from the work itself, his absorbability of Western culture has been fully integrated into his own traditional pen and ink, the proximity of such strokes has produced another aesthetic connotation, not just the hypotaxis of the surface. Huang Binhong was standing from the traditional aspect to find similarity or likeness between western culture and eastern culture to extract the essence to enrich their language of painting.

\section{B. The Promotion of National Culture}

"Take calligraphy into painting" has become the spirit of philosophy runs through Chinese painting. In 20th century's Chinese painting circles, there are rare painters like Huang 
Binhong who strongly emphasized the importance of take calligraphy into painting. Huang was deeply aware of the importance of calligraphy to painting, and he has cleaved to these principles all his life. "I often use landscape as words and use words in painting." The "black" style in his old age has unchanged law in the external performance, which is the "Take calligraphy into painting, every line is clear." Seemingly the drawing was casual without order, but in fact the pen force is strong, vertical and horizontal strokes overlap with s strict order. In Huang Binhong's youth time, he seriously studied the "Shimen Song" and many other different styles of tablet inscriptions of the Northern Dynasties; in his middle-aged time ,he concentrated on research of Xingshu, especially focus on Yan Zhenqing's "Zhengzuoweitie"; in his old age, he dedicated in inscriptions on ancient bronze objects, the pencraft is round heavy and energetic. In his "vigorous" painting style, we can find the "vigorous" origins, if not for years of practicing in various calligraphy, so he understood the true essence of calligraphy, therefore there would not be thousands of vigorous points in his later years works as fulcrum behind his "black" style, so there is no such mass ink paintings like the "Yangzhou Baguai" or "Zhe pai", but with clear lines and ink. Even dyed, also with calligraphy pencraft, in this way the dyed color has thickness. Huang Binhong firmly grasp the "Take calligraphy into painting" which is the foundation of Chinese painting in order to make his "black" painting more powerful.

\section{THE CREATION METHOD}

\section{A. The Use of Pen and Ink}

From Huang Binhong repeatedly emphasized the "Take calligraphy into painting" concept can be seen how seriously he pay attention to the pen. Huang studied and copied calligraphy of various factions, he had a unique experience on how to use the pen in painting. On the basis of summarizing the previous works, he proposed a "Five pen crafts", which are Ping, Yuan, Liu, Zhong and Bian. Huang extracted stone calligraphy in calligraphy and introduced the stone calligraphy temperament into painting, to enhance the sense of rough and unadorned sense of his pen. It also strengthened the awareness of pen's quality, enhanced the quality of pen and ink. His unusual calligraphy pencraft gets ahead of many ancient people. If we interpret the "black" rhyme of his works, then Taiji pencraft like a brick and a tile constructing his entire painting. The "gou" and "le" like iron nails and silver hooks extremely chisel on the paintings strongly, the entire painting is made up of numerous "Gou", "Le" and the spawned pen crafts such like long-line, short-line, cracked, rub, point, dyeing and others together to constitute the cell body produced by the "black" rhyme. Huang Binhong studied calligraphy for his lifetime, use "Tai Chi pencraft" resolve "Pima Cun", "Jiesuo Cun" etc., integrated his apperception after years study of "Nanzong" pencraft into his own skills of pen and ink and then developed countless rough and strong large ,small dots and short, long lines. In his works after 80 years age, overlapping between lines, interleaving between dots and rhythmed combination between dots and lines, this simple and pure structural forms make the "black" of his works more calm and easy and also with beating diversity. The "stone falling from mountain" pencraft force and the skilled pencraft make the "black" loudly, vivid and expressive. The overlapping between lines also have space, this is what Huang said "properly use the pen, the cuns cross each other but not chaos, cuns avoid each other without touch". Huang Binhong also through plot points into a line, organic combination between lines, some fake cross, fake access, some slightly cross, slightly access, and some overlap, in the use of lines he reached one breath on and one breath out. The breath of "Gou", "Le" brought the breathing rhythm of the entire "black" rhythm, thus enhancing the form of beauty in the picture.

The pen and ink game interest which is drawn by Huang Binhong makes his works seem not from the real rivers and mountains, but look like the different versions consist of the pen and ink symbols. As Shen Kuo discussed Dong Yuan's painting, "very hastily in pen use, from close look it does not like image; but from a distance look, the scene is vivid and with heavy emotions seems like watching the real image." Close look at Huang Binhong's paintings, each stroke and each ink did not attach a specific image, it seems arbitrary but from a distance look it is lush, seems everything is there and this is more in line with the true face of nature. This formal beauty composed with pen and ink alienates between the representational and the abstract, it is the inner beauty of nature of the universe, and also the conveyance as a visual psychological style. Influenced by Western modernist and fauvism, the ink lines and colors in Huang Binhong's paintings like prints overprint error from in expression, there is a kind of dislocation overlapping sense, seems rough and chaos, in fact, this is his conveyance of an order in disorder, he use numerous strokes to convey his understanding of the universe spirit. Through crude chaos lines to express the harmony calm atmosphere of the landscape.

Huang Binghong was good at using ink, has had unique skills in ink use, the application of Jimo fa and Simo fa in the "Seven ink methods" can be said that Huang Binhong had beyond the ancients and he used those two methods the most in his works. It can be said Huang Binhong's pencraft and ink craft complement each other, the normal painters in ink accumulation process, three times is their limit, some better painters are able to do four or five times, Huang Binhong can reach a dozen times, but the picture is still breathable, pen and contained each other, stroke marks and ink shades together to achieve seamless effect. In addition, he also found that point sumo dots after point heavy ink, so the dark place is lighted up by ink dots which formed "light ink", his ink crafts change amazingly.

The use of old ink was not created by Huang Binhong. The sink waste contained in old ink was easy to make the picture dirty and chaos, so it was difficult for most artists to use. But there were features in old ink that new ink did not have, which was sense of texture. If used well, it could change the dirty sense caused by sediment in the ink into clean sense. Add old ink into thick ink and the old ink will break the thick, light break the thick, thick break the light, Huang Binhong masterly uses these three ink methods of Jimo, Sumo and Pomo. 


\section{B. The Introduction of Light Perception}

The painting theory said: "The ancient people said, mountains were divided into Morning Sun Mountain, Setting Sun Mountain and Noon Mountain. Because the sun shines obliquely, the Morning Sun Mountain and Setting Sun Mountain are semi-shady and smoke everywhere with clouds deposition." Thus we can see that the ancient people already have observation to the natural light. But throughout the traditional Chinese landscape paintings, such as "Early Spring" and "Magpie in autumn" just use light as a intervention method, so the expression of light perception in the picture was not intense. The application of light for Western impressionist inspired Huang Binhong in a certain degree, and his use Qin philosophical concept of black and white, false and true, "Knowing White and Guarding Black", he combined the light application and traditional philosophy together, created a new technique. He called this technique "living eye", of course, this technique is unprecedented. "Painting like play chess, it requires a good use of living eye, more living eyes mean win. So called living eye is the virtual of painting."

Huang Binhong did not directly borrow the Western technology mode of fixed light source, his expression of light focused on the harmony and unity, rich and subtle, the light used positive astigmatism and left several local "living eyes", the length intersection of the "line" used echo connection dense and varied ways to make the "black" in picture became move and charm. The connection formed by several dotted lines like what Huang Binhong called "Dragon and snake in painting ", their overall image could be cloud, mountain road, streams. In fact, from screen configuration, these dotted lines connected the image ideas from up to bottom, from left to right and formed the overall momentum. Combination of "live eye" and "dotted line" was also a clever application of Huang Binhong's "Tai Chi strokes", and it showed his understanding and usage for traditional art essence already known by heart.

\section{Selection of Painting Content}

For an artist who takes landscape painting as his main creative direction, observe and "sightseeing tour" are essential, they are the necessary external factors to form his personal painting style and painting quality, everyone is inevitable, only in various degrees. We can see from Huang Binhong's life, he has repeatedly traveled all over the mountains and rivers, his draft sketches reached more than ten thousands sheets, plus his research on "Yinmian Shan" in Northern Song Dynasty, this combination of tradition heritage and learn from nature built a solid foundation for the "black" mountain works in Huang Binhong's old age, and he created many night mountains based on this, in the picture he uniquely weakened the specific images, emphasized merging rhythm of ink and water, fully focused on the first feeling and expressed his feelings through simple lines vividly, so that to make the expressing smooth. It can be said Huang Binhong's grasp of the natural objects had advantages and strengths which were different with other painters, we often see Huang's landscape works, the revealing smart mountains with signs of life seemed slowly moved forward, although they were just about simple mountains, but there was a momentum in them. I always believe that this is one of the factors for Huang Binhong's success, it is his deeply grasp and experience about the spirit and soul of the mountains which he was born with. This unique experience achieved his success, he also found his own uniqueness, and exerted his unique experience to nature into a variety of subject matters. Since Huang Binhong observed the mountain in night alone for several times, he had unique experience for the intangible, back and intense, hazy mountains under the moon. He released his whole body and mind, forgot the time and space he was in, the flesh seemed no longer a mortal bondage so that his soul can be better integrated with nature. Night mountain painting is also one of Huang Binhong's most representative works, it fully embodied this point. His application of Jimo, Sumo and Pomo methods is more suitable to express the mystery and deep of the nigh mountains. He abstracted the beauty of night mountain, it can be said at this time the mountain has reached the realm of mountains is not mountain, water is not water, it was completely became spiritual sustenance and expression under Huang Binhong's pen and ink, it has already become bearing material of spirit and soul. This is the crystal of Huang Binhong's life experience and life perception which is also his self-transcendence. We can say that Huang Binghong had a spiritualism which many other painters do not have and the unique natural feeling to the nature. Otherwise the simple night mountain is nothing but only a mountain at night, it objectively erected there without any connotation or any signs of life inside, it just like a body without a soul. The reason Huang Binhong became a master, not only he chose the themes which complement with his technique, but also he operated the picture as a living life to make his paintings "live" up with flesh and blood, formed a "black" Landscape Art . At the same time he took the variability of pen and ink with the richness of nature's own harmony together, these factors have converged in his "Night Mountain" creations. So in Huang Binhong's creation "Night Mountain" works, the "black" was rich, natural, bright and stratified. The "black" of Huang Binhong's paintings conveyed "vigorous and flourishing, simple and precipitous" "dry autumn wind and moist spring rain" means. Huang Binhong's landscape paintings reflected more deeply, spiritual and smooth in the aesthetic sense of pen and ink abstract symbol. He deeply excavated the essence of nature, tried to wake up inner "self" and the mountains "inner beauty" together to reflect the "nature sense". He observed "Own mind" and understood the inner beauty in still state to express a humanistic spirit and literati feelings. Huang Binhong's pen and ink interest alienated between similar and dissimilar, forming a unique pen and ink interest and constructed a unique emotional expression mode to transfer the dialogue between soul and landscape.

\section{CONCLUSION}

While Huang Binhong inheriting the tradition, learn from the nature, he boldly absorbed the essence of Western art and combined the three in his own pen and ink organizational structure, formed the style of "black" as landscape feature. Huang Binhong focused on tradition, "Take calligraphy into painting", developed the previous pen craft and ink craft, combined with stone sphragistics and painting theories to enrich his own pen and ink temperament. He borrowed western's light understanding, skillfully introduced light perception into the picture, light up the "black" soul" with "live 
eye", showed "vigorous" aesthetic position. He injected new blood into Chinese landscape painting with brand new painting appearance, and left a glorious chapter in the history of art. At the same time he opened a new chapter in landscape painting and established another artistic peak.

\section{REFERENCES}

[1] Liu Wei. Graphic gallery of Chinese artistic master - Huang Binhong .Shanxi Education Press, 2006.

[2] Lu Fusheng, Cao Jinyan. Huang Binhong Collection · painting articles (Shang). Shanghai Fine Arts Publishing Company, 1999.

[3] Shu Shijun. From traditional literati painting to modern ink and wash. Fudan University Press, 1998.

[4] Yang Yinglin. Graphs of Chinese famous painters and paintings.Huang Binhong.Renmin University of China Press, 2003. 